\title{
ANALISIS STRATEGI PEMASARAN PRODUK SMARTPHONEVIVO DI TELEMARCO PADA INTERNATIONAL PLAZA PALEMBANG
}

\author{
Iin Hendrayani \\ Sekolah Tinggi Ilmu Ekonomi Mulia Darma Pratama \\ $e$-mail : iin.hendrayani1988@gmail.com
}

\begin{abstract}
ABSTRAK
Penelitian analisis strategi pemasaran produk smartphone Vivo telah dilakukan di Telemarco pada Internasional Plaza (IP) Palembang. Tujuan penelitian ini adalah untuk mengetahui strategi pemasaran pada produk Smartphone Vivo di International Plaza Palembang. Penelitian ini merupakan jenis penelitian deskriptif dengan menggunakan metode penyajian data kualitatif yang dianalisis menggunakan metode SWOT dengan menggambarkan objek penelitian berdasarkan kekuatan, kelemahan, peluang dan ancaman. Teknik pengumpulan data dilakukan dengan cara Studi Kepustakaan (Library Research) dan Penelitian Lapangan (Field Research) melalui observasi dan wawancara. Adapun hasil penelitian yang didapat bahwa strategi pemasaran Smartphone Vivo di Perusahaan Telemarco meliputi strategi produk, strategiharga, promosi dan strategi pemilihan tempat. Hasil yang diperoleh dari penelitian ini adalah Ada tiga strategi pemasaran Smartphone Vivo di Perusahaan Telemarco yang telah dilajankan meliputi strategi produk yang membangun brand image/citra merek, strategi harga meliputi pembelian cash dan kredit, Strategi promosi berupa iklan di media Televisi, Koran dan Online serta brosur promo dan pemberian hadiah. Strategi Pemasaran yang telah dilakukan Perusahaan Telemarco pada dasarnya telah sesuai dengan hasil analisis SWOT yang dilakukan terhadap produk Smartphone Vivo yang meliputi unsur strategi bauran pemasaran seperti Produck, Price, Promotion, dan Place. Saran yang dapat diberikan penulis dalam penelitian ini, sebaiknya produk Vivo memberikan hadiah-hadiah kepada konsumen serta kemudahaan untuk membeli dengan cicilan atau juga berupa vocher potongan harga agar menarik minat konsumen untuk membeli. Analisis strategi pemasaran perlu dilakukan setiap tahun agar perusahaan selalu mendapatkan alternatif strategi baru yang lebih inovatif sehingga tujuan untuk mencapai market leader pemasaran dapat tercapai.
\end{abstract}

Kata Kunci: Strategi Pemasaran, Analisis SWOT, Smartphone Vivo

\begin{abstract}
Research of marketing strategy of Vivo smartphone products has been done at Telemarco at the Palembang International Plaza (IP). The purpose of this study was to find out the marketing strategy of the Smartphone Vivo product at the Palembang International Plaza. This research is a type of descriptive research using the method of presenting qualitative data which is analyzed using the SWOT method by describing the object of research based on strengths, weaknesses, opportunities and threats. Data collection techniques are carried out by means of Library Research and Field Research through observation and interviews. The results obtained from this study are that there are three marketing strategies of Vivo Smartphone in Telemarco Company which have been implemented include product strategies that build brand image, pricing strategies include cash and credit purchases, promotional strategies in the form of advertisements in Television, Newspapers and Online media as well as promo brochures and gift giving. The marketing strategy that has been carried out by the Telemarco Company is basically in accordance with the results of the SWOT analysis conducted on Vivo Smartphone products which include elements of marketing mix strategies such as Produck, Price, Promotion, and Place. Suggestions that can be given by the author in this study, Vivo provides gifts to consumers and the ease of buying by installments or also giving discount prices to attract consumers to buy. Marketing strategy analysis needs to be done every year so that the company always gets a new alternative strategy that is more innovative so that the goal to reach market marketing leaders can be achieved.
\end{abstract}


Keywords : Marketing Strategy, SWOT Analysis, Smartphone Vivo.

\section{PENDAHULUAN}

Perkembangan dibidang teknologi terutama teknologi dibidang telepon genggam atau Handphone sangat pesat dari waktu ke waktu, sehingga perkembangan tersebut dapat mempengaruhi dunia usaha. Perkembangan ini tentunya akan semakin mengarah pada persaingan ketat khususnya untuk perusahaan sejenis. Persaingan dapat terjadi dari segi teknologi yang ditawarkan, ataupun harga yang relatif rendah. Setiap perusahaan dituntut untuk memiliki suatu keunikan tersendiri yang dapat memikat konsumen dalam rangka mempertahankan atau merebut pangsa pasar yang ada.

Perkembangan Smartphone semakin meningkat, sehingga mendorong perusahaan besar untuk menciptakan produk yang lebih baik lagi salah satunya adalah perusahaan Vivo. Perusahaan Vivo berasal dari Dongguan, Guangdong Tiongkok. Pada Tahun 2009 yang didirikan oleh Shen Wei. Meskipun Vivo produk baru di Indonesia tetapi dia mampu bersaing dan menduduki perinkat 5 besar di indonesia. Vivo yang memilik seri $\mathrm{Y}$ dan $\mathrm{V}$ dintaranya Y15, Y95, Y91 dan V7, V9. Smartphone yang menggunakan Vivo bervariasi diantaranya karyawan, pelajar, mahasiswa, wanita karir, pengusaha, dan masyarakat semua kalangan.

Semua organisasi membutuhkan pemasaran untuk mencapai tujuan dan objektifnya, jadi perusahaan memerlukan strategi berbeda-beda guna jangka panjang, yang digunakan bagi pedoman masing-masing tingkat perusahaan (Wicaksono, 2018: 193).

Tingginya permintaan Smartphone tidak terlepas dari strategi pemasaran yang dimiliki oleh perusahaan tertentu. Masing-masing perusahaan berlomba-lomba dalam hal menawarkan fitur atau konten menarik yang dimiliki oleh Smartphone andalan mereka sehingga diharapkan konsumen akan membeli Smartphone yang mereka jual.

Strategi merupakan suatu tindakan yang digunakan untuk mencapai tujuan perusahaaan dan mencapai keunggulan bersaing. Dilihat dari konteks bisnis, strategi menggambarkan arah bisnis yang mengikuti lingkungan yang dipilih dan merupakan pedoman untuk mengalokasikan sumber daya dan usaha suatu organisasi. secara umum dapat diartikan sebagai rencana yang disusun oleh perusahaan untuk mencapai tujuan yang telah ditentukan (Indrapraja, 2015:44).

Menurut Prakoso (2017:69) Ada berbagai macam tools strategi pemasaran yang dapat digunakan oleh sebuah perusahaan, salah satunya adalah SWOT yang meliputi strength, weakness, opportunitiess, dan threat. Namun, faktor-faktor SWOT tersebut perlu diidentifikasi besaran dampaknya terhadap tujuan perusahaan, yakni strategi pemasaran. bahwa Analisis SWOT ialah identifikasi berbagai faktor secara sistematis untuk merumuskan suatu strategi perusahaan. Analisis SWOT terdiri dari dua faktor internal (strength dan weakness) yang mengidentifikasi kebaikan dan keburukan kinerja perusahaan dan dua faktor eksternal (opportunitiesdan threat) yang mengidentifikasi potensi kemudahan dan gangguan pada kinerja perusahaan untuk mencapai tujuan perusahaan.

Hasil wawancara dengan distributor smartphone Vivo di Palembang tingginya permintaan konsumen sangat mempengaruhi peningkatan penjualan, ditambah dengan harga dan kualitas yang ditawarkan oleh smartphone Vivo bersaing dengan merek smartphone idaman konsumen yang berharga mahal.

Tabel 1

Total Penjualan Smartphone Vivo Dalam Satu Tahun 2018

\begin{tabular}{|c|c|c|r|}
\hline \multirow{2}{*}{ Bulan } & \multicolumn{3}{|c|}{$\begin{array}{c}\text { Penjualan Smartphon } \\
\text { Vivo (Unit) }\end{array}$} \\
\cline { 2 - 4 } & $\mathbf{2 0 1 6}$ & $\mathbf{2 0 1 7}$ & $\mathbf{2 0 1 8}$ \\
\hline Januari & 12 & 15 & 17 \\
\hline Februari & 10 & 17 & 17 \\
\hline Maret & 15 & 19 & 19 \\
\hline April & 12 & 23 & 20 \\
\hline Mei & 15 & 20 & 21 \\
\hline Juni & 11 & 18 & 24 \\
\hline Juli & 16 & 25 & 26 \\
\hline
\end{tabular}




\begin{tabular}{|c|c|c|c|} 
Agustus & 20 & 28 & 28 \\
\hline September & 23 & 30 & 31 \\
\hline Oktober & 30 & 29 & 30 \\
\hline November & 31 & 40 & 40 \\
\hline Desember & 35 & 53 & 55 \\
\hline Total & $\mathbf{2 3 0}$ & $\mathbf{3 1 7}$ & $\mathbf{3 2 8}$ \\
\hline
\end{tabular}

(Sumber data: Observasi langsung distributor smartphone Vivo di International Plaza).

Dari tabel 1 di atas penjualan smartphone Vivo di tahun 2016-2018 yaitu 875 unit, mengalami peningkatan setiap tahunnya. Target penjualan Vivo terus meningkat, pada tahun 2016 target penjualan Vivo di International Plaza adalah 150 unit. Pada tahun 2016 Vivo terjual sebanyak 230 unit, penjualan melebihi target sebanyak 80 unit. Peningkatan penjualan di tahun 2016 adalah 53\% dari target 150 unit. Pada Tahun 2107 target penjualan Vivo adalah 250 unit. meningkat $26 \%$ dari target yang ada. Peningkatan terjadi karena adanya promosi harga dan adanya hadiah yang diberikan berupa case, memory dan kartu internet. Pada tahun 2018 target penjualan Vivo adalah 400 unit. Tahun 2018 target penjualan Vivo tidak tercapai. Pada tahun 2018 hanya terjual 328 unit $<18 \%$ dari target yang ingin dicapai, karena persaingan produk yang sangat ketat. Dari permasalahan tersebut, peneliti tertarik melakukan penelitian tentang "ANALISIS STRATEGI PEMASARAN PRODUK SMARTPHONE VIVO DI TELEMARCO PADA INTERNATIONAL PLAZA PALEMBANG".

\section{METODOLOGI PENELITIAN}

\section{Strategi}

Strategi adalah suatu proses penentuan rencana para pemimpin puncak yang berfokus pada tujuan jangka panjang organisasi, disertai penyusunan suatu cara atau upaya agar tujuan tersebut dapat tercapai.

\section{Strategi Pemasaran}

Strategi pemasaran merupakan rencana yang menjabarkan ekspektasi perusahaan akan dampak dari berbagai aktivitas atau program pemasaran terhadap permintaan produk atau lini produknya di pasar sasaran tertentu.

\section{Analisis SWOT}

Menurut Galavan (2014) dalam Amalia (2016: 299) bahwa, analisis SWOT metode perencanaan strategis yang digunakan untuk mengevaluasi kekuatan (strenghts), kelemahan (weaknesses), peluang (opportunities), dan ancaman (threats).

\section{METODO PENELITIAN}

\section{Objek Penelitian}

Objek penelitian dalam penelitian ini adalah distributor Smartphone Vivo di Telemarco pada International Plaza Palembang.

\section{Metode Penelitian}

Penelitian ini menggunkana metode deskriptif menurut Nazir, 2011: 52, yaitu metode untuk mencari unsur-unsur, sifat-sifat suatu fenomena dengan mengumpulkan data, menganalisis, mendeskripsikan dan menginterpretasikan data yang diperoleh melalui studi kepustakaan dan penelitian lapangan.

\section{Metode Analisis Data}

Metode analisis yang digunakan dalam penelitian ini adalah metode kualitatif, menggunakan metode analisis SWOT (strengths, weaknesses, opportunities and threats).

Dalam penelitian ini potensial pokok persoalan yang harus diperhatikan dalam melakukan analisis SWOT:

1. Potensial kekuatan (strengths) Internal meliputi: Merek Vivo sudah dikenal luas atau Brad Image,Harga smartphone Vivo relatif murah, teknologismartphone yang canggih, kepercayaan dan respek pada Produk Vivo tinggi, kemampuan Vivo bersaing di pasar nasion al dan internasional. Kualitas produk yang superior, kemampuan distribusi yang baik, Karyawan yang berkomitmen dalam pemasaran,

2. Potensial Kelemahan (weaknesses) Internal meliputi: Kurangnya pemasaran dan promosi smartphone Vivo, produk smartphone Vivo yang terbatas, terbatasnya distribusi, mahalnya harga smartphone Vivo, teknologi smartphone Vivo yang ketinggalan jaman, imej pasar yang lemah, kemampuan pemasaran yang kurang baik oleh distributor atau karyawan yang tidak terlatih.

3. Potensial Peluang (opportunities) Eksternal meliputi: Permintaan pasar terhadap smartphone Vivo meningkat, produk 
pesaing yang sudah merasa puas diri, kebutuhan dan keinginan konsumen, terbukanya pemasaran luar negeri, produksi smartphone Vivo terbaru, teknologi Vivo diperbarui setiap tahun, ekonomi yang meningkat, penolakan akan subtisusi produk, Perubahan metode distribusi.

4. Potensial Ancaman (threats) eksternal meliputi kompetitor smartphone lain, produk baru dari kompetitor yang lebih menarik, perubahan kebutuhan dan keinginan konsumen, kepercayaan konsumen yang berkurang, produk pesaing mengadopsi strategi baru, ekonomi yang mengalami penurunan, teknologi canggih dari smartphone kompetitor, Lemahnya kinerja perusahaan/distributor.

\section{HASIL DAN PEMBAHASAN}

Dalam memasuki persaingan pasar suatu perusahaan tentu telah memiliki strategi pemasaran yang disusun sedemikian rupa agar produk-produk yang ditawarkan dapat bersaing di pasar. Objek penelitian ini adalah pemasaran smartphone Vivo di Telemarco pada Internasional Plaza (IP) Palembang, sehingga data-data yang diambil dalam penelitian ini terkait dengan smartphone Vivo di Telemarco pada Internasional Plaza (IP) Palembang.

\section{Strategi yang Digunakan Di Perusahaan Telemarco.}

Strategi pemasaran sangat penting dimiliki oleh suatu perusahaan agar produk dapat bersaing. Sales promosi bertujuan untuk mengenalkan produk yang di jual prusahaan kepada konsumen. Pengalaman usaha yang telah di miliki oleh Perusahaan Telemarco berpengaruh terhadap keberhasilan Pemasaran. Keberhasilan tersebut tidak terlepas dari strategi yang digunakan dalam hal pemasaran produk. Salah satu contoh yang dilakukan dalam bauran pemasaran yakni strategi promosi, perusahaan biasanya menggunakan sales dalam melakukan kegiatan promosi yang lebih dikenal dengan Sales Promotion/Sales Promosi. Dalam hal ini, perusahaan Telemarco Memberikan biasanya memberikan insentif penjualan kepada Sales Eksekutif dan Sales Counter yang mendapatkan penjualan smartphone Vivo terbanyak melalui sales promosi. Hal inilah yang membuat produk Vivo ditawarkan terlebih dahulu oleh para konsumen agar bisa mendapatkan bonus penjualan tersebut. Menurut Utami Manager pemasaran di Internasional Plaza (IP) Palembang bahwa pihaknya selalu memberikan bonus kepada karyawan yang mendapatkan penjualan terbaik terhadap smartphone Vivo.Kekuatan pemasaran yang ada pada karyawan diharapkan mampu menjadikan kekuatan bagi distributor smartphone Vivo.

Menurut perusahaan Telemarco salah satu distributor yang menjual berbagai produk smartphone Vivo di Palembang, strategi pemasaran yang mengandung unsur meliputi:

1. Strategi Produk meliputi kualitas produk, citra merek, dan telemarco menjamin kerusakan pada produk apabila saat pembelian ada kerusakan.

2. Strategi Harga, perusahaan menetapkan dan mempertahankan harga yang bersaing sesuai dengan kualitas smartphone Vivo. Mempermudah konsumen dalam pembelian baik secara tunai maupun kredit dengan mennggunakan KTP.

3. Strategi Promosi Perusahaan Telemarco melakukan kegiatan pemasaran dengan memasang spanduk dengan brand ambasador-nya disetiap toko dengan Tagline Vivo adalah "Perfect Selfie.". ,memberi hadiah berupa case, memorry, dan kartu internet. Selain itu juga pembagian brosur promo gebyar Agustus Serta perusahaan Telemarco selalu menjaga komunikasi kepada konsumen sehingga menciptakan comited buyer.

\section{Analisis SWOT Smartphone Vivo di Perusahaan Telemarco.}

Untuk mengeksplorasi strategi pemasaran smartphone Vivo di Telemarco pada Internasional Plaza (IP) Palembang, diawali dengan deskripsi perkembangan pemasaran smartphoneVivo. Untuk mengetahui strategi pemasaran pada smartphone Vivo di Perusahaan Telemarco Palembang perlu dilakukan analisis sederhana, dalam hal ini analisis Swot dapat digunakan untuk mengetahui strategi pemasaran. Analisiss SWOT dilakukan dengan melihat faktor internal dan eksternal produk Vivo dengan menganalisis kekuatan (Strength) dan kelemahan (Weakness), faktor peluang (Opportunity) dan Ancaman (ThreathS).

Berdasarkan hasil wawancara yang dilakukan kepada staf perusahaan didapatkan hasil kekuatan, kelemahan, peluang dan ancaman (SWOT) dari smartphone Vivo di 
perusahaan Telemarco Palembang sebagai berikut:

1. Kekuatan (Strength) meliputi: Brand Image atau merek dikenal luas, Kualitas produk superior, Teknologi smartphone canggih, Kepercayaan atau respek konsumen pada produk, dan Harga sesuai kualitas produk,

2. Kelemahan (Weakness) meliputi: Marketing yang terlalu berlebihan dan Build quality masih perlu improvement

3. Peluang (Opportunity) meliputi: Permintaan pasar cukup tinggi, Adanya kebutuhan dan keinginan konsumen terhadap smartphone, Pemasaran nasional dan internasional.

4. Ancaman (Threaths) meliputi: Produk pesaing menurunkan harga, Produk pesaing lebih menarik. Perubahan keinginan konsumen, Ekonomi mengalami penurunan.

Adapun alternatif strategi yang bisa dilakukan smartphone Vivo untuk mempertahankan produk di pasar berdasarkan hasil SWOT di atas diantaranya sebagai berikut:

1. Alternatif strategi Strength-Opportunity (S-O) didapatkan dengan menggunakan kekuatan untuk mendapatkan peluang. Strategi yang bisa dilakukan sesuai dengan hasil analisis yaitu:

a. Mempertahankan serta menciptakan produk baru dengan kualitas yang diinginkan konsumen.

b. Memperluas target baik pemasaran langsung ataupun online.

Dari hasil wawancara dengan Utami manager toko perusahaan telemarco di International plaza beliau mengatakan pembeli mencari smartphone di konter kami kebanyakkan mengiginkan jenis smartphone yang memiliki kualitas terbaik, baik dari segi kamera, kapasitas baterai maupun RAM/ROM.

Selain menginginkan kualitas smartphone terbaik pembeli juga tertarik dengan harga yang murah. Smartphone Vivo yang kami tawarkan kepada pelanggan sangat disambut baik, bahkan tidak jarang pelanggan yang mencari smartphone memutuskan untuk membeli smartphone Vivo karena kualitas dan harga yang ditawarkan sangat sesuai. Salah satu pelanggan kami juga telah percaya dengan produk smartphone Vivo, karena setiap memutuskan untuk mengganti smartphone dia langsung kepada produk Vivo. Target pemasaran kami tidak hanya di konter- konter yang kami miliki, kami juga memperluas pemasaran smartphone melalui pasar online.Kepercayaan konsumen terhadap produk sangatlah penting dalam strategi pemasaran. Membangun kepercayan konsumen dapat dilakukan dengan pemasangan iklan-iklan tentang produk. Iklan didefinisikan sebagai pesan yang menawarkan suatu produk yang ditujukan kepada masyarakat lewat suatu media.

2. Strategi Weakness-Opportunity (W-O) didapatkan dengan meminimalkan kelemahan untuk memanfaatkan peluang, alternatif strategi yang diperoleh yaitu :

a. Mengurangi promosi yang terlalu berlebihan yang bisa menunjukkan image produk vivo menurunt, meminimalisir biaya pengeluaran.

b. Memperbaiki body product dan memperhatikan build quality ponsel.

Tanggapan dari manager toko Telemarco di International Plaza harga smartphone Vivo yang di jual di konter kami sangat bersaing dengan produk kompetitor smartphone yang memiliki spesifikasi sama. Bahkan menurut beberapa konsumen harga smartphone Vivo jauh lebih murah dibandingkan dengan beberapa merek smartphone dari korea yang sangat terkenal di Indonesia.

3. Strategi Strength-Threaths (S-T), menciptakan strategi yang menggunakan kekuatan untuk mengatasi ancaman, hasilnya didapatkan alternatif strategi yaitu:

a. Menetapkan dan mempertahankan harga yang bersaing.

b. Meningkatkan promosi.

Iklan diantarnya melalui pemberian cashback, media online dan adanya pameran di luar toko dengan bantuan Sales Forse tujuannya adalah mencari penjualan sebanyak-banyaknya dalam waktu sesingkat-singkatnya melalui transaksi penjualan. Sales forces ini ada yang bersifat langsung maupun tidak langsung. Yang bersifat langsung adalah para SPG (Sales Promotion Girls) dan supervisor yang berhadapan langsung dengan pasar dan konsumen.

Sedangkan yang tidak langsung adalah para brand ambassador yang bersamaan dengan iklan memasarkan produk Vivo melalui media dengan cakupan pasar yang sangat luas.

4. Strategi Weakness-ThreathS (W-T), yang didapatkan dengan meminimalkan kelemahan dan menghindari ancaman maka didapatkan strategi. hasilnya didapatkan alternatif strategi yaitu: mempertahankan hubungan baik dengan pelanggan/konsumen. 
Contoh dalam strategi ini perusahaan Telemarco memberikan pelayanan terbaik dengan adanya purna jual, jaminan suku cadang, garansi produk, dan pemberian hadiah kepada konsumen yang telah menjadi pelanggan setia perusahaan.

Dari hasil Analisis alternatif strategi SWOT diatas, strategi yang dihasilkan terdapat unsur strategi bauran pemasaran meliputi Produck, Price, Promotion, dan Place.

\section{Product}

Produck yang memiliki Brand Image atau citra merek atau kepercayaan yang ada dalam benak konsumen untuk menjadi pembeda dari merek yang lainnya seperti lambang, desain huruf atau warna khusus dan kualitas produk merupakan kemampuan suatu perusahaan untuk memberikan identitas atau ciri pada setiap produk sehingga konsumen dapat mengenali produk.

2. Price

Price merupakan salah satu elemen dari bauran pemasaran. Harga memainkan peranpenting dalam pemasaran untuk penjualan danpembelian. Harga salah satu pemacu minat konsumen untuk membeli. Strategi harga pembelian secara tunai dan pembayaran mencicil cukup menggunakan KTP konsumen.

3. Promotion

Promotion merupakan suatu bentuk komunikasi pemasaran yang merupakan aktivitas pemasaran berusaha menyebarkan informasi, membujuk/mempengaruhi dan atau meningkatkan pasar sasaran atas perusahaan atau produknya agar bersedia menerima, membeli, dan loyal pada produk yang ditawarkan perusahaan yang bersangkutan. Salah satu media mempromosikan diantaranya dengan menggunakan media iklan, radio, televisi, majalah, koran. Untuk menambah minat konsumen adanya promosi pemberian hadiah berupa case, memorry, dan kartu internet.

4. Place

Place merupakan suatu wadah yang digunakan untuk memasarkan suatu produk dan faktor penting untuk memaksimalkan pemasaran agar yang ditawarkan tepat sasaran. Menetapkan lokasi yang tepat agar produk yang ditawarkan dengan mudah didapatkan oleh konsumen yang membutuhkan. Lokasi yang dipilih diantaranya konter-konter contohnya pasar 9/10 Ulu, pasar 16 Ilir. Adapun untuk memperluas area pemasaran diadakannya event-event di Musi Banyuasin dan mall.

\section{KESIMPULAN DAN SARAN}

\section{Kesimpulan}

Berdasarkan hasil penelitian yang telah dilakukan pada Telemarco di International Plaza Palembang, dapat disimpulkan sebagai berikut:

1. Strategi pemasaran Smartphone Vivo di Perusahaan Telemarco yang telah dijalankan meliputi strategi produk yang membangun brand image/citra merek, strategi harga meliputi pembelian cash dan kredit, Strategi promosi berupa iklan di media Televisi, Koran dan Online serta brosur promo dan pemberian hadiah, strategi tempat yang memaksimalkan penjualan dengan menentukan lokasi sasaran.

2. Strategi Pemasaran yang telah dilakukan Perusahaan Telemarco pada dasarnya telah sesuai dengan hasil analisis SWOT yang dilakukan terhadap produk Smartphone Vivo yang meliputi unsur strategi bauran pemasaran seperti Produck, Price, Promotion, dan Place.

\section{Saran}

sebagai berikut:

1. Sebaiknya produk Vivo memberikan banyaknya hadiah- hadiah kepada konsumen serta kemudahan untuk membeli dengan cicilan dan vocher potongan harga agar menarik minat konsumen untuk membeli.

2. Analisis strategi pemasaran perlu dilakukan setiap tahun agar perusahaan selalu mendapatkan alternatif strategi baru yang lebih inovatif sehingga tujuan untuk mencapai market leader pemasaran dapat tercapai.

\section{DAFTAR PUSTAKA}

Amalia, A. 2016. "Perencanaan strategi pemasaran dengan pendekatan bauran pemasaran dan swot pada perusahaan popsy tubby". Jurnal Manajemen dan Start-Up Bisnis. Surabaya: Fakultas 
Manajemen Bisnis, Universitas Ciputra. Volume 1, Nomor 3.

Indrapraja, RMI, dkk. 2015. "Strategi Komunikasi Pemasaran Jungleland Adventure Theme Park Bogor Dalam Upaya Menarik Pengunjung”. Jurnal Komunikatio. Bogor: Fakultas Ilmu Sosial dan Ilmu Politik Universitas Djuanda. ISSN 2442-3882. 1:1.

Nazir. M, Ph.D. 2011. "Metode Penelitian". Jakarta : Ghalia Indonesia.

Prakoso, A.B. dkk. 2017. "Analisis Strategi Pemasaran Produk Kosmetik Wardah dengan Pendekatan SWOT-AHP (Analytic Hierarchy Process)". Jurnal Sains Dan Seni Institut Teknologi Sepuluh November : Surabaya. Vol.6 no.01-ISSN: 2337-3520.

Wawancara Pribadi dengan Utami Ayu (Manager pemasaran Perusahaan Telemarco di Internasional Plaza ), Palembang 15 April 2019. Pada Pukul 13.00 WIB.

Wicaksono, A. 2018. "Strategi Pemasaran dengan menggunakan Analisis SWOT

Tanpa Skala Industri Pada PT X Di Jakarta”. Jurnal Management Industri dan Logistik, Jakarta: Program studi Manajemen Pemasaran Industri ElektronikaPoliteknik APP. Vol 1: N0.2 